\section{Estudo \\ CoDebate}

em Testão

Plamejamento
Revista Estudo \& Debate, Lajeado, v. 24, n. 1, 2017. ISSN 1983-036X

DOI: http://dx.doi.org/10.22410/issn.1983-036X.v24i1a2017.1246

\title{
A PROTEÇÁO DO PATRIMÔNIO, SEGUNDO A ONU, A UNESCO E A CONSTITUIÇÃO FEDERAL BRASILEIRA
}

\author{
Andrea Almeida Barros ${ }^{1}$, Luciana Turatti ${ }^{2}$
}

\begin{abstract}
Resumo: Quando se fala em proteção ao patrimônio, logo se pensa em uma das diferentes listas do Patrimônio Mundial editadas pela Organização das Naçôes Unidas para Educação, Ciência e Cultura (UNESCO) a cada dois anos, todas inscrevendo bens de expressivo valor universal ao redor do mundo, que passam por um processo de avaliação pela comissão criada junto ao organismo para esta finalidade, bem como pela aceitação da inscrição pelo Estado-Parte. Por outro lado, há outras classificações trazidas pela Organização das Naçóes Unidas (ONU), especialmente no tocante ao uso da água doce, dos rios navegáveis, do uso do fundo do mar e da lua, bem como pela Constituição Federal do Brasil, que instituiu o inovador conceito de patrimônio socioambiental, de interesse transindividual. O objetivo deste estudo é propiciar uma ampla visão desses conceitos que, por estarem dispostos em diferentes fontes documentais, acabam por gerar confusão quanto a sua instituição, objetivos e limites de atuação para a efetiva proteção patrimonial, trazendo-se uma análise crítica e se provendo uma lacuna científica ante a falta de artigos científicos para esta finalidade. Utiliza-se o método qualitativo quanto ao modo de abordagem, tratando-se de investigação exploratória. A pesquisa bibliográfica e documental são as bases do referencial teórico. Embora existam diferentes classificações do patrimônio a ser protegido, eles não se confundem. Com estes conceitos em mente, tem-se um panorama dos diferentes tipos de patrimônio existentes, que devem ser preservados por estarem gravados como de interesse transindividual e transgeracional.
\end{abstract}

Palavras-chave: Patrimônio Cultural. Patrimônio Natural. Patrimônio da Mundial da Humanidade. Patrimônio Comum da Humanidade. Patrimônio Partilhado.

\section{THE DIFFERENT KINDS OF HERITAGE, ACCORDING TO THE UN, UNESCO AND THE FEDERAL CONSTITUTION OF BRAZIL}

\begin{abstract}
When it comes to protecting our heritage, soon if you think in one of the different lists of World Heritage edited by the United Nations Educational, Scientific and Cultural Organization (UNESCO) every two years, all subscribing property of explicit universal value around the world, who go through a process of evaluation by the Commission created by the body for this purpose, as well as by the acceptance of registration by
\end{abstract}

1 Promotora de Justiça da Promotoria de Justiça Especializada de Estrela. Promotora designada para a Promotoria Regional de Meio Ambiente. Coordenadora do Programa de Recuperação Sustentável da Mata Ciliar do Rio Taquari/RS. Mestranda em Ambiente e Desenvolvimento no Centro Universitário Univates Lajeado/RS.

2 Doutora de Direito pela UNISC. Professora do curso de Direito da UNIVATES. Professora no PPGAD da UNIVATES. 
the State Party. On the other hand, there are other classifications made by the United Nations (UN), especially with regard to the use of fresh water, of navigable rivers, the use of the bottom of the sea and the moon, as well as by the Federal Constitution of Brazil, who introduced the innovative concept of environmental heritage, of interest transindividual. The objective of this study is to provide a broad overview of these concepts, which are prepared in various documentary sources, ultimately lead to confusion as to their institution, objectives and limits of action for effective asset protection, bringing a critical analysis and providing a scientific gap compared to the lack of scientific articles for this purpose. We use the qualitative method as to how to approach, when it comes to exploratory research. The bibliographic and documental research are the basis of the theoretical framework. Although there are different classifications of assets to be protected, they will not get confused. With these concepts in mind, you have an overview of the different types of existing assets, which should be preserved by being recorded as of interest transindividual and transgeracional.

Keywords: Cultural Heritage. Natural Heritage. World Heritage of Mankind. Common Heritage of Mankind. Shared Heritage.

\section{INTRODUÇÁO}

Quando se fala em proteção ao patrimônio da humanidade, imediatamente faz-se uma remissão à Lista do Patrimônio Mundial editada pela Organização das Nações Unidas para Educação, Ciência e Cultura (UNESCO) a cada dois anos. E são diferentes as listas produzidas, em que se inscrevem bens de expressivo valor universal ao redor do mundo, que passam por um processo de avaliação pela comissão criada junto ao organismo para esta finalidade, bem como pela aceitaçáo do registro pelo Estado-Parte.

Mas não é só a UNESCO que trata do tema patrimônio. Outras classificaçôes são provenientes da Organização das Naçóes Unidas (ONU) e também da Constituição Federal Brasileira. Todas visam, igualmente, a tutela integral dos bens protegidos, porque de interesse coletivo. Com isso, busca-se evitar que eles sejam destruídos, garantindo, assim, que as próximas geraçóes deles possam também usufruir.

De que forma essa proteçấo ao patrimônio é efetivada por esses organismos internacionais? Como esses bens são classificados? Por estarem albergadas em diferentes Convençóes e Tratados Internacionais, o que denota certa dificuldade de conhecimento das espécies de patrimônio e de seus limites protetivos, entendeu-se pertinente alinhar, num mesmo artigo científico, já que inexistente outro, as diferentes classificaçóes trazidas pela UNESCO e pela ONU, conceituando-as, pois a literatura pesquisada é direcionada a uma ou outra classificação, apenas. É importante destacar que o Brasil é signatário de diversos tratados internacionais, tendo por obrigação proteger os bens de interesse da humanidade que se localizam no seu território.

O objetivo, além de se propiciar essa visão global do que UNESCO, ONU e Constituição Pátria entendem por patrimônio, é demonstrar a forma como são classificados os bens, quais são os objetivos e os limites da proteção em si, de acordo com sua política própria. Também, de que forma os Estados-Parte devem agir para respeitar as regras internacionalmente impostas para a proteção desse patrimônio que pertence à humanidade e se ela se dá de forma efetiva. Ainda, apontar patrimônios internacionalmente protegidos pela UNESCO e pela ONU e que se encontram em território brasileiro. 


\section{REFERENCIAL TEÓRICO}

\subsection{Os tipos de patrimônio}

De etimologia latina, conforme o Dicionário Houaiss (2001), patrimonium referese a bem de família, herança recebida e, figurativamente, à riqueza. Também se relaciona com bem ou conjunto de bens naturais ou culturais de importância reconhecida num determinado lugar, região, país e até para a humanidade. Para tanto, faz-se necessário passar por um processo denominado de tombamento para, somente após, receberem o manto da proteção e da preservação.

Trata-se de um conjunto de bens que a geração presente recebeu da anterior, sem qualquer mérito, e que não continuará a existir sem o seu apoio, segundo Machado (2014). $\mathrm{O}$ autor ainda lembra que esse patrimônio pode ser desfrutado pela presente geração, que, por sua vez, não poderá prejudicar a sua fruição pela vindoura. Trata-se de respeito ao Princípio da Preservação Intergeracional, citado por Gomes (2008) e previsto na Carta Magna de 1988.

\subsubsection{Patrimônio cultural material e imaterial (ou intangível)}

$\mathrm{O}$ perigo de degradação e de desaparecimento que os bens culturais e naturais estavam sofrendo, tendo em vista a proteção insatisfatória exercida pelos países em que se localizam, desencadeou a ação protetiva da UNESCO. A fim de tutelar e preservar o patrimônio considerado de interesse excepcional, a instituição, na sua Conferência Geral de 1972, aprovou a Convenção para Proteção do Patrimônio Mundial, Cultural e Natural (UNESCO, 1972).

Para tanto, definiu, em seu artigo primeiro, o que integra o patrimônio cultural: são os monumentos (obras arquitetônicas, esculturas, pinturas monumentais, etc., de valor universal excepcional do ponto de vista da história, da arte ou ciência); os conjuntos (grupos de construçóes isoladas ou reunidas que, por sua arquitetura, unidade ou integração à paisagem, têm valor universal excepcional sob os mesmos pontos de vista antes referidos) e os sítios (obras do homem ou conjugadas entre homem e natureza, sítios arqueológicos de valor universal excepcional do ponto de vista histórico, estético, etnológico ou antropológico) (UNESCO, 1972). O Brasil é signatário desta Convenção, pois publicou o Decreto $\mathrm{n}^{\circ}$ 80.978/1977, promulgando-a e autorizando o reconhecimento internacional de patrimônio cultural e natural em solo brasileiro (BRASIL, 1977) ${ }^{3}$.

Note-se que o artigo primeiro descreve apenas o que compóe o patrimônio cultural material. Entretanto, em 2003, a UNESCO editou a Convenção para Salvaguarda do Patrimônio Cultural Imaterial, abrangendo as tradiçóes e expressóes vivas herdadas dos antepassados e transmitidas à geração futura. Cita-se como exemplo: as tradições orais, usos

3 O primeiro sítio arqueológico brasileiro inscrito como Patrimônio Mundial da UNESCO foi a cidade histórica mineira de Ouro Preto, em 1980. De lá para cá, ingressaram na lista os centros históricos de Olinda/PE, de Salvador/BA, de Sáo Luis/MA, de Diamantina/MG, de Goiás/GO, também a cidade de Brasília/DF, as Ruínas de São Miguel das Missôes/RS etc. (UNESCO, 2015). 
sociais, rituais, atos festivos, conhecimentos e práticas relativas à natureza (conhecimentos tradicionais), saberes e técnicas vinculadas ao artesanato etc. (UNESCO, 2003). O patrimônio imaterial, apesar de frágil, tem o objetivo de manter presente a diversidade cultural em face de um mundo globalizado e de contribuir para o diálogo intercultural, promovendo o respeito entre diferentes culturas, pois se trata de algo contemporâneo, que está sendo vivido atualmente (UNESCO, 2003). O artigo $2^{\circ}$ da mencionada Convenção traz as seguintes definiçốes:

Artigo 2: Definições Para os fins da presente Convenção,

1. Entende-se por "patrimônio cultural imaterial" as práticas, representaçóes, expressóes, conhecimentos e técnicas - junto com os instrumentos, objetos, artefatos e lugares culturais que lhes são associados - que as comunidades, os grupos e, em alguns casos, os indivíduos reconhecem como parte integrante de seu patrimônio cultural. Este patrimônio cultural imaterial, que se transmite de geração em geração, é constantemente recriado pelas comunidades e grupos em função de seu ambiente, de sua interação com a natureza e de sua história, gerando um sentimento de identidade e continuidade e contribuindo assim para promover o respeito à diversidade cultural e à criatividade humana. Para os fins da presente Convenção, será levado em conta apenas o patrimônio cultural imaterial que seja compatível com os instrumentos internacionais de direitos humanos existentes e com os imperativos de respeito mútuo entre comunidades, grupos e indivíduos, e do desenvolvimento sustentável.

2. O "patrimônio cultural imaterial", conforme definido no parágrafo 1 acima, se manifesta em particular nos seguintes campos: a) tradiçōes e expressóes orais, incluindo o idioma como veículo do patrimônio cultural imaterial; b) expressôes artísticas; c) práticas sociais, rituais e atos festivos; d) conhecimentos e práticas relacionados à natureza e ao universo; e) técnicas artesanais tradicionais.

O Brasil, antecipando-se à UNESCO, passou a reconhecer a existência de patrimônio imaterial com a promulgação da Constituição Federal de 1988, que, em seus artigos 215 e 216, refere que os bens culturais podem ser materiais ou não (BRASIL, 1988; BRASIL, 2016; UNESCO, 2015). No ano de 2000, editou o Decreto no 3.551, que regulamenta o instituto do registro, utilizado para a inscrição dos bens imateriais como patrimônio protegido (BRASIL, 2000), "tendo como referência a continuidade histórica do bem e sua relevância nacional para a memória, a identidade e a formação da sociedade brasileira" (AMADO, 2013). Apenas em 2006 foi publicado o Decreto no 5.753/2006, que promulgando a Convenção para a Salvaguarda do Patrimônio Cultural Imaterial, adotada em Paris, em 17 de outubro de 2003, e assinada em 3 de novembro de 2003 (BRASIL, 2006).

\subsubsection{Patrimônio cultural subaquático}

Em 2001, a UNESCO criou a Convenção sobre a Proteção do Patrimônio Cultural Subaquático, que compreende os rastros da existência humana que estejam ou tenham estado submersas, parcial ou totalmente e que, obviamente, tenham um caráter cultural e histórico de importância, abrangendo os naufrágios, paisagens subaquáticas, cavernas etc. (UNESCO, 2001). No Brasil, tramitou no Congresso Nacional o Projeto de Lei no 45/2008, que tratava sobre o tema. Como não foi apreciado em tempo hábil, foi encaminhado ao arquivo no final de 2014, conforme informaçóes obtidas junto ao sítio do Senado Federal. 
Resta, portanto, vigente a Lei no $7.542 / 86$, que dispóe sobre a pesquisa, exploração, remoçấo e demolição de coisas ou bens afundados, submersos, encalhados e perdidos em águas sob a jurisdição nacional, em terreno de marinha e seus acrescidos e em terrenos marginais, em decorrência de sinistro, alijamento ou fortuna do mar e dá outras providências. Esta lei nada refere quanto ao patrimônio cultural subaquático, nos termos da Convençáo antes referida (BRASIL, 1986).

\subsubsection{Patrimônio natural}

Retomando a Convenção para Proteção do Patrimônio Mundial, Cultural e Natural, editada em 1972 pela UNESCO, verifica-se que o artigo segundo define o que é Patrimônio Natural. Este é composto por: i) monumentos naturais (formaçóes físicas e biológicas ou conjuntos de formaçóes de valor universal excepcional do ponto de vista estético ou científico); ii) formaçôes geológicas e fisiográficas e as zonas estritamente delimitadas que constituam habitat de espécies animais e vegetais ameaçadas, que sejam de valor universal excepcional do ponto de vista estético ou científico; bem como os iii) sítios naturais estritamente delimitados, detentores de valor universal excepcional do ponto de vista da ciência, da conservação ou da beleza natural (UNESCO, 1972).

O primeiro patrimônio natural reconhecido pela UNESCO, no Brasil, foi o Parque Nacional de Iguaçu, em 1986. Mais tarde, em 1999, a Mata Atlântica e a Mata Costeira também foram declaradas patrimônio. Depois, foram inscritas a Floresta Amazônica, o Pantanal (ambos em 2000) e, finalmente, em 2001, as Ilhas Atlânticas Brasileiras (Fernando de Noronha e a Reserva de Atol das Rocas) e as Áreas de Cerrado (Chapada dos Veadeiros e Parque Nacional das Emas), conforme o sítio da UNESCO (2016).

\subsubsection{Patrimônio socioambiental ou de interesse público}

No tocante ao patrimônio socioambiental, Souza Filho (1997) refere que ele surgiu no Brasil com a Constituição Federal de 1988, não se contrapondo aos já conhecidos patrimônio público e privado, mas somando a eles um conceito de imaterialidade, ou seja, uma qualidade ambiental humanamente referenciada, tornando o bem gravado de titularidade da coletividade. Esses bens, prossegue o autor, também são chamados de bens de interesse público. Para Silva (2001, p. 161), "O que importa é que alguns bens ficam subordinados a um peculiar regime jurídico relativamente a seu gozo e disponibilidade e também a um particular regime de polícia, de intervenção e de tutela pública”. E aqui é indiferente se a propriedade desse bem ambiental é pública ou privada, pois o regime que lhe é imposto em razão de seu interesse público é o que a caracteriza, a fim de preservar a qualidade de vida, atributo essencial desse conceito constitucional (SILVA, 2001).

Para Piva (apud FRANCO, 2005, p. 79), por outro lado, o bem socioambiental tem natureza jurídica difusa. Isto porque se trata, ainda segundo o autor, de "[...] um bem protegido por um direito que visa assegurar um interesse transindividual, de natureza indivisível, de que sejam titulares pessoas indeterminadas e ligadas por circunstâncias de fato". 


\subsubsection{Patrimônio transfronteiriço}

Por transfronteiriço se entende aquilo que vai além da fronteira, pois o vocábulo latino trans significa, conforme o Dicionário Houaiss (2001), "além de", "para lá de", "depois de". Logo, patrimônio transfronteiriço é aquele que transcende às fronteiras de um Estado soberano, como, por exemplo, os rios e as águas subterrâneas (CAMPANA, 2005).

Amorim (2009) revela que foi na Convenção de Viena, ocorrida em 1814, que houve a definição do que eram rios transfronteiriços e sucessivos, após os países participantes reconhecerem a importância da navegação. Nesta oportunidade, os rios foram classificados em internos (dentro dos limites de um Estado) e internacionais (atravessam ou dividem dois ou mais Estados soberanos). Por rio transfronteiriço entende-se aquele que serve de limite entre Estados e por rio sucessivo aqueles que cortam ininterruptamente dois ou mais Estados (AMORIM, 2009).

Por outro lado, há as Áreas Protegidas Transfronteiriças (APT), que, segundo a União Internacional para a Conservação da Natureza - UICN (apud RIO, 2010), são as porções terrestres ou marítimas que abrangem uma ou mais fronteiras entre Estados e têm por objetivo a proteção e a manutenção da diversidade biológica, dos recursos naturais e dos culturais que lhe são associados. Estes espaços são geridos através de cooperação legalmente instituída entre, pelo menos, dois governos diferentes sendo possível a participação de outros atores locais (UICN, 2008). Segundo Rio (2010), a Bacia do Alto Paraguai, que abrange os países do Brasil, Bolívia e Paraguai, é um exemplo de APT.

\subsubsection{Patrimônio partilhado}

Se a Convenção de Viena deu início à forma de utilização dos rios navegáveis, nada referiu quanto à proteção da água doce, componente natural e essencial para a manutenção dos padróes de qualidade de vida e do meio ambiente, para a regulação do clima e para a continuidade de determinados setores produtivos, conforme Amorim (2009). A água doce em si, portanto passou a ser vista como algo a ser protegido, especialmente após as constataçóes acerca da poluição e degradação dos mananciais e das fontes existentes no planeta (AMORIM, 2009).

Em 1997, com o objetivo de garantir a utilização, o desenvolvimento, a conservação, a gestão e a proteção dos cursos de água doce, a Assembleia Geral das Naçóes Unidas adotou a Convenção sobre o Direito Relativo à Utilização dos Cursos de Água Internacionais para Fins Diversos dos de Navegação. Consoante o artigo primeiro, segundo item, as águas navegáveis estão excluídas da presente convenção.

Dentre as definiçóes constantes no artigo segundo da mencionada Convenção, verifica-se que curso de água é considerado como "um sistema de águas superficiais e subterrâneas que constituem, em razão da sua relação física, um conjunto unitário e que normalmente fluem para um término comum" (ONU, 1997, texto digital). Já o curso de água internacional é aquele que possui parcelas situadas em Estados diferentes, trazendo o artigo terceiro as regras gerais para que eles firmem acordos para a utilizaçáo desses cursos de água, demonstrando tratar-se de um patrimônio partilhado (ONU, 1997). 
Entretanto, a doutrina, especialmente Machado (2009), entende que a água deve ser considerada um recurso natural comum e não um patrimônio partilhado como atualmente se define. Isso porque o "[...] traço marcante não é a propriedade da coisa, mas a fruição dos serviços que a coisa presta ou é idônea a prestar, se convenientemente utilizada", segundo Giannini (apud MACHADO, 2009, p. 69).

Machado (2009) defende que os Estados que partilham a água doce proveniente de um curso hídrico internacional devem ter consciência do papel social dela. Devem dela se utilizar dentro de seu território sem que o Estado vizinho seja prejudicado, gerando um tipo especial de comportamento deste usuário: a cooperaçáo preventiva e transparente, pois a água comum representa a riqueza dos Estados ribeirinhos, conforme consta na Declaraçáo de Princípios da Comunidade Econômica Europeia.

\subsubsection{Patrimônio mundial da humanidade}

Segundo Zanirato (2010), um bem considerado patrimônio mundial da humanidade, de acordo com a Convenção da UNESCO (1972), e diferentemente da Convenção do Mar (ONU, 1982) ou do Acordo que Regula as Atividades dos Estados na Lua e em Outros Corpos Celestes ${ }^{4}$, publicado pela Organização das Nações Unidas (ONU), em 1979, não pode ser designado como propriedade de todas as pessoas, embora seja de interesse comum a sua preservação. Humanidade, no seu entender e sob o enfoque da primeira convenção, significa que as pessoas podem fruir de tais bens, mas jamais deles dispor.

Para que um determinado bem seja considerado capaz de integrar a lista do Patrimônio Mundial da Humanidade da UNESCO, a Convenção para Proteção do Patrimônio Mundial, Cultural e Natural de 1972 exige que ele seja de excepcional interesse, o que faz com que sua preservação seja necessária para a humanidade5. Em 1977, a UNESCO editou o documento denominado Directrices Prácticas para La aplicación de La Convención Del Patromónio Mundial, em que define, no seu artigo 49, o que significa a expressão retrocitada (UNESCO, 1977, texto digital):

Valor Universal Excepcional significa una importancia cultural y/o natural tan extraordinaria que trasciende las fronteras nacionales y cobra importancia para las generaciones presentes y venideras de toda la humanidad. Por lo tanto, la protección permanente de este patrimonio es de capital importancia para el conjunto de la comunidad internacional. El Comité define los criterios de inscripción de los bienes en la Lista del Patrimonio Mundial.

Os critérios adotados pelo Comitê Intergovernamental para a Proteção do Patrimônio Mundial, Cultural e Natural, para a inscrição de um determinado bem na Lista do Patrimônio Mundial, foram definidos no artigo 77 do mesmo documento, devendo o bem candidato à inscriçáo preencher um ou mais requisitos, conforme se trata de bem cultural

4 Conhecido como Tratado da Lua.

5 "Considerando que determinados bens do patrimônio cultural e natural se revestem de excepcional interesse que necessita a sua preservação como elementos do patrimônio mundial da humanidade no seu todo" (UNESCO, 1972). 
ou natural. Além disso, o bem deve estar íntegro e/ou ser autêntico, e também contar com um sistema de proteção e gestão adequado, a fim de garantir a sua salvaguarda (artigo 78).

Concluído o processo de análise (cujos detalhes procedimentais encontram-se nesse mesmo documento) de um bem candidato a integrar a Lista dos Bens Mundiais da UNESCO e entendendo o Comitê que ele preenche os critérios antes mencionados, deve o Estado-Parte, que tem legitimidade para propor o processo, concordar com a inscrição. A Lista deve ser atualizada a cada dois anos, conforme alínea $2^{a}$ do artigo 11 da Convençáo para a Proteção do Patrimônio Mundial, Natural e Cultural (UNESCO, 1972).

\subsubsection{Patrimônio comum da humanidade}

A ideia de patrimônio comum da humanidade se encontra presente tanto no Tratado da Lua (ONU, 1979), como na Convenção das Nações Unidas sobre os Direitos do Mar (CNUDM, 1982). A primeira traz em seu artigo 11, alínea 1, que "A Lua e seus recursos naturais são patrimônio comum da humanidade, como expressam as cláusulas do presente Acordo, [...]", devendo os Estados-Parte que tiverem interesse na exploraçáo definirem e publicizarem o modo como pretendem utilizar, dando a conhecer ao Secretário-Geral da $\mathrm{ONU}$, à população e à comunidade científica. Ou seja, qualquer Estado-Parte pode explorar esse patrimônio, desde que atenda às condiçóes do Acordo. De se salientar que o Brasil não é dele signatário.

Por outro lado, a Convenção sobre os Direitos do Mar veio a corrigir um entendimento que se percebeu equivocado com o passar dos anos. Se antes se defendia que os bens marinhos eram de propriedade de todos (res communnis, no dizer de Pureza (2002)) e, por conseguinte, qualquer Estado poderia explorar o mar além de sua área de soberania (chamada de Área", que se refere ao leito do mar, fundos marinhos e subsolo marinho), desde 1982 a exploração somente é permitida mediante regras internacionais a serem observadas pelos Estados-Parte, que não poderão reivindicar, nem se apropriar ou exercer soberania ou direitos de soberania sobre qualquer parte da Área ou seus recursos (ONU, 1982).

A Convenção das Nações Unidas sobre o Direito do Mar (CNDUM) foi celebrada na Jamaica, em 1982, e determinou tratar-se o mar de um repositório de bens que interessam à humanidade. Por isso, definiu as normas para a sua utilização. Segundo Zanirato (2010), o alto mar, portanto, é um espaço aberto a todos os Estados indistintamente, sejam costeiros ou não. Logo, os bens ali havidos pertencem à humanidade em geral, náo podendo ser apropriados. Além disso, prossegue a autora, devem ser utilizados para finalidades pacíficas e "devem beneficiar a todos os estados e a todos os homens" (ZANIRATO, 2010, texto digital).

Trata-se, portanto, de um patrimônio que a todos pertence, mas que não pode ser apropriado por ninguém. Difere do patrimônio previsto na Convençấo de 1972, pois

6 Bem comum. 
este continua sendo de propriedade do Estado-Parte em que está situado, mas que todos, indistintamente, têm o direito de dele usufruir.

\section{METODOLOGIA}

Este artigo, que é de revisão (bibliográfica e documental), será desenvolvido utilizandose o método qualitativo quanto ao modo de abordagem, tratando-se de investigação exploratória. A pesquisa bibliográfica é a base do referencial teórico trazido à lume.

A primeira parte da pesquisa ocorreu nos sítios da UNESCO e da ONU, a fim de coletar as diferentes convençóes e tratados que versam sobre patrimônio da humanidade. Como resposta, foram encontrados os seguintes documentos: Convenção para a Proteção do Patrimônio Mundial, Cultural e Natural (1972); Directrices Prácticas para la aplicación de la Convención del Património Mundial (1977); Patrimônio Cultural Subaquático (2001) e Convenção para Salvaguarda do Patrimônio Cultural Imaterial (2003), todos editados pela UNESCO. Do sítio da ONU foram retiradas a Convenção das Naçóes Unidas sobre os Direitos do Mar (1982) e a Convenção sobre o direito relativo à utilização dos cursos de água internacionais para fins diversos dos de navegação (1997), bem como o Acordo que regula as atividades dos Estados na lua e em outros corpos celestes (1979). Ainda, no sítio da UNESCO pesquisou-se a lista atualizada dos bens inscritos como Patrimônio da Humanidade, especialmente no Brasil.

De posse desses documentos, a pesquisa foi direcionada ao sítio do Congresso Nacional Brasileiro, a fim de verificar a legislação protecionista brasileira, em especial a Constituição Federal de 1988. Também, para verificar os decretos que declaram o Brasil como signatário dos tratados, acordos e convenções internacionais.

Utilizando-se das expressóes "patrimônio cultural”, "patrimônio natural”, "patrimônio mundial da humanidade"; "patrimônio comum da humanidade", "patrimônio partilhado" e seus correlatos nos idiomas inglês, francês e espanhol, buscou-se, em bancos de dados digitais (EBSCO, Science Direct, Scielo, ResearchGate), bem como publicados em eventos de pesquisa científica (ANNPAS) e bibliotecas digitais brasileiras e de universidades portuguesas (Lisboa e Coimbra) pelo estado da arte sobre o tema, sendo que retornaram 138 artigos. Foram utilizados cinco que tratavam diretamente do assunto, sendo dispensados os demais, que traziam abordagem secundária, sem vínculo direto com o objeto do estudo. Além deles, buscou-se pela literatura tradicional e moderna que trata do assunto.

A pesquisa se limitou aos conceitos de patrimônio trazidos pela UNESCO, pela ONU em suas normativas e pela Constituição Federal Brasileira. No tempo, limitou-se a pesquisa até dezembro de 2015, quando o presente artigo foi desenvolvido.

\section{DISCUSSÓES E RESULTADOS}

Ao longo das últimas décadas, percebendo a necessidade de proteção de diferentes patrimônios que deveriam ser preservados para que as geraçóes futuras também possam dele usufruir, é que tanto a ONU quanto a UNESCO buscaram a tutela deles. Para tanto, editaram tratados, convençóes e acordos, que podem vir a ser assinados pelos EstadosParte, ou não. Para que o Brasil se torne signatário dessas determinaçóes, é imprescindível 
a aprovação de um Decreto no Congresso Nacional, de forma a tornar vigente no país a legislação internacional, em face da soberania estatal, que lhe é peculiar.

O Brasil, embora signatário de diversos tratados, convençóes e acordos internacionais, com a edição da Constituição Federal de 1988, que trouxe o conceito de Patrimônio Socioambiental, desconhecido até então, ingressou na esfera protecionista ante a inovação. O objetivo é proteger o meio ambiente ecologicamente equilibrado, necessário à sadia qualidade de vida dos brasileiros, agregando-se, segundo Silva (2001), a ideia de equilíbrio e qualidade ambiental àquela expressão. Envolve, diretamente, a relação entre o homem e o meio ambiente em que vive.

Não se pode confundir o patrimônio socioambiental com o natural, protegido pela UNESCO. Enquanto o primeiro trata da relação dinâmica entre o homem e seu habitat, cujo equilíbrio ecossistêmico é primordial, este se refere a locais denominados de monumentos naturais, formações geológicas e fisiográficas e sítios naturais, não levando em consideração o equilíbrio ecossistêmico e nem a relação desses locais com o ser humano.

A UNESCO, na mesma convenção que determinou a proteção do patrimônio natural (1972), trouxe o conceito de patrimônio material como sendo algo tangível, descrevendo-os como monumentos, conjuntos e sítios. Com isso, não protegeu a cultura, o conhecimento e os costumes que são transmitidos de geração a geração. A fim de reconhecer essas manifestaçóes como patrimônio, neste caso intangível ou imaterial, editou a Convenção que as protege em 2003. O objetivo é a preservação da continuidade histórica, importante para a formação da cultura, da memória, da história e da formação da identidade de um povo (AMADO, 2013). Entretanto, o Brasil antecipou-se ao órgão internacional, já que previu essa proteção em 1988, quando da promulgação da sua Carta Magna.

O Brasil é signatário destas duas Convençóes, ao contrário daquela que instituiu o patrimônio subaquático. Por motivos desconhecidos, o projeto de Lei no 45/2008 (BRASIL 2008) foi arquivado no Congresso Nacional sem votação. Patrimônio subaquático, como o próprio nome diz, refere-se aos bens que sejam de interesse coletivo - por sua história ou importância cultural - e que se encontram submersos.

Permanecendo no ambiente aquático, foi em Viena (1814) que se reconheceu a importância das águas dos rios navegáveis, fossem eles internos (da nascente à foz em um mesmo território) ou externos (AMORIM, 2009), sendo classificado como patrimônio transfronteiriço. Neste caso, o rio ou era limítrofe entre dois países, ou era sucessivo, atravessando mais de dois Estados. Além destas duas possibilidades, Rio (2010) traz outro exemplo desta espécie de bem de interesse coletivo: as Áreas Protegidas Transfronteiriças (APT), criadas pela União Internacional para a Conservaçáo da Natureza (UICN) e gerenciado através da cooperaçáo dos governos dos Estados envolvidos e de atores locais. Percebe-se que, nestes casos, em havendo um dano ambiental em um dos territórios envolvidos, as consequências facilmente alcançam os demais, daí a importância do cuidado e do zelo equânime pelo patrimônio entre os envolvidos.

A água doce também passou a ser protegida, tendo em vista tratar-se de um recurso finito e que serve a diferentes povos. A ONU instituiu, assim, o Patrimônio Partilhado através da Convenção sobre o Direito Relativo à Utilização dos Cursos de Água 
Internacionais para Fins Diversos dos de Navegação (1997). Não há propriedade definida nesta espécie de patrimônio, já que a todos serve. Machado (2009) entende que a água deve ser compreendida como patrimônio comum, e náo partilhado, tendo em vista os serviços que presta e a sua imprescindibilidade para a vida na terra. Ademais, requer cooperação preventiva e transparente entre os Estados envolvidos, a fim de que conflitos sejam evitados (MACHADO, 2009).

Entretanto, não há como se concordar com Machado, pois a ONU trouxe o conceito de Patrimônio Comum da Humanidade, solidificado no Tratado da Lua (1979) e na Convenção das Nações Unidas sobre os Direitos do Mar (CNUDM, 1982). Nestes casos, o patrimônio pertence a todos, indistintamente, e qualquer Estado pode ter acesso, para fins científicos, ao fundo do mar - áreas gerais - e à Lua. Entretanto, deve haver a comunicação do seu uso à ONU e aos demais Estados-Parte. Nenhum Estado pode dispor desse patrimônio, embora possa, dentro de seus interesses científicos, financiar pesquisas tanto no mar, quanto na lua e em outros corpos celestes. A água doce é partilhável porque é vital para a manutenção da vida, exigindo-se que todos dela se beneficiem diretamente e sem qualquer espécie de comunicação prévia àquele organismo internacional.

Patrimônio Comum da Humanidade e Patrimônio Mundial da Humanidade não se confundem. Enquanto aquele foi instituído pela $\mathrm{ONU}$ e a todos pertence, este é instituído, após um processo administrativo, pela UNESCO, mas a sua propriedade permanece com o Estado em que está localizado. O interesse comum é de que ele seja preservado (ZANIRATO, 2009). Para integrar uma das listas de Patrimônio emitidas pelo referido organismo internacional, o bem deve possuir valor excepcional universal. Por outro lado, o Estado-Parte, em cujo território se localiza o bem, deve propor o processo e, depois de aprovado, aceitar expressamente a sua inscrição, pois disso demandam as ações de preservação para a atual geração e as futuras, obedecendo à lógica da proteção intra e intergeracional (GOMES, 2008).

\section{CONSIDERAÇÓES FINAIS}

Com esses conceitos reunidos em um mesmo artigo, tem-se um panorama dos diferentes tipos de patrimônio atualmente existentes, que devem ser preservados por estarem gravados como de interesse transindividual e transgeracional. Também, consegue-se apurar os objetivos protetivos insertos em cada um deles, bem como a origem da sua instituição, se ONU, UNESCO ou Constituição Brasileira. Também é possível se compreender como se dará a efetiva proteção, pois a partir do momento em que os Estados se tornam signatários das Convençóes, Tratados e Acordos, assumem para si a responsabilidade protetiva, sob a fiscalização dos organismos internacionais e, em alguns casos, dos demais Estados-Parte, como, por exemplo, o caso do patrimônio partilhado ou transfronteiriço, em que a conduta inadequada de um prejudica diretamente o outro.

Nos casos em que o patrimônio fora instituído pela UNESCO e o Estado signatário não atende à proteção e preservação plena do patrimônio mundialmente declarado, pode haver o auxílio, inclusive financeiro, daquela para que se efetive a proteção. O que se discute é se isso afronta, ou não, a soberania dos países, tema a ser abordado em outro momento, por não integrar o escopo deste estudo. 


\section{REFERÊNCIAS}

AMADO, F. Direito Ambiental Esquematizado. 4. ed. revista, atualizada e ampliada. São Paulo: Editora Método, 2013.

AMORIM, J. A. A. Direito das Águas. O regime jurídico da água doce no Direito Internacional e no Direito Brasileiro. São Paulo: Lex Editora Ltda., 2009.

BRASIL. Decreto no 80.978, de 12 de dezembro de 1977. Promulga a Convenção Relativa à Proteção do Patrimônio Mundial, Cultural e Natural, de 1972. Disponível em: <http://legis.senado.gov.br/legislacao/ListaNormas.action? numero=80978\&tipo_ norma=DEC\&data=19771212\&link=s $>$. Acesso em: 02 jan. 2016.

Lei no 7.542, de 26 de setembro de 1986. Dispõe sobre a pesquisa, exploração, remoção e demolição de coisas ou bens afundados, submersos, encalhados e perdidos em águas sob a jurisdição nacional, em terreno de marinha e seus acrescidos e em terrenos marginais, em decorrência de sinistro, alijamento ou fortuna do mar e dá outras providências. Disponível em: <http://www.planalto.gov.br/ccivil_03/leis/L7542.htm. Acesso em: 06 dez. 2015.

. Constituição (1988). Constituiçáo Federativa do Brasil. Disponível em: <http://www.planalto.gov.br/ccivil_03/constituicao/ConstituicaoCompilado.htm>. Acesso em: 05 dez. 2015.

. Decreto no 3.551, de 04 de agosto de 2000. Institui o Registro de Bens Culturais de Natureza Imaterial que constituem patrimônio cultural brasileiro, cria o Programa Nacional do Patrimônio Imaterial e dá outras providências. Disponível em: <http://www. planalto.gov.br/ccivil_03/decreto/D3551.htm>. Acesso em: 02 jan. 2016.

Decreto no 5.753, de 12 de abril de 2006. Promulga a Convenção para a Salvaguarda do Patrimônio Cultural Imaterial, adotada em Paris, em 17 de outubro de 2003, e assinada em 3 de novembro de 2003. Disponível em: <http://www.planalto.gov. br/ccivil_03/_ato2004-2006/2006/decreto/d5753.htm>. Acesso em: 02 jan. 2016.

. Senado Federal. Projeto de Lei no 45/2008. Disponível em: <http://www25. senado.leg.br/web/atividade/materias/-/materia/84559>. Acesso em: 15 dez. 2015.

. Instituto do Patrimônio Histórico e Artístico Nacional. Patrimônio Imaterial: 2016. Disponível em: <http://portal.iphan.gov.br/pagina/detalhes/234>. Acesso em: 02 jan. 2016.

CAMPANA, Michael E. Foreword: Transboundary Ground Water. Ground Water. Vol. 43, no 5, Setembro-Outubro 2005, p. 646. 
FRANCO, C. A. de O. O Município e a questão socioambiental: bases jurídicas para uma gestão local sustentável. 2005. 124 f. Dissertação (Mestrado em Direito Econômico e Social) - Pontifícia Universidade Católica do Paraná, Curitiba, jul. 2005. Disponível em: $<$ http://www.biblioteca.pucpr.br/tede//tde_busca/arquivo.php?.codArquivo=500>. Acesso em: 06 dez. 2015.

GOMES, C. A. O Direito ao Ambiente no Brasil: um olhar português. In:

Textos Dispersos de Direito do Ambiente. I vol. Lisboa: AAFDL, 2008. p. 273-291.

HOUAISS, A. Dicionário Houaiss. 1. Ed. Rio de Janeiro: Objetiva, 2001.

MACHADO, Paulo A. L. Direito dos cursos de água internacionais. São Paulo: Malheiros, 2009.

MACHADO, P. A. L. Direito Ambiental Brasileiro. 22. ed. revista, ampliada e atualizada. São Paulo: Malheiros Editores, 2014.

ONU. Acordo que regula as atividades dos Estados na lua e em outros corpos celestes. ONU, 1979. Disponível em: <http://daccess-dds-ny.un.org/doc/RESOLUTION/GEN/ NR0/383/97/IMG/NR038397.pdf?OpenElement>. Acesso em: 02 jan. 2016.

. Convenção das Naçóes Unidas sobre os Direitos do Mar. ONU, 1982.

Disponível em: <http:/www.icmbio.gov.br/cepsul/images/stories/legislacao/

Decretos/1995/dec_1530_1995_convencaonacoesunidassobredireitomar.pdf>. Acesso em: 02 jan. 2016.

Convenção sobre o direito relativo à utilização dos cursos de água internacionais para fins diversos dos de navegaçáo. ONU, 1997. Disponível em: <http://legal.un.org/ilc/texts/instruments/english/conventions/8_3_1997.pdf>. Acesso em: 02 jan. 2016.

PUREZA, J. M. El patrimonio común de la humanidad. Madrid: Editorial Trotta, 2002.

RIO, G. A. P. do. Desafios de gestão ambiental em espaços periféricos transfronteiriços: patrimônio natural e territórios na bacia do Alto Paraguai. In: ENCONTRO NACIONAL DE PÓS-GRADUAÇÃO E PESQUISA EM AMBIENTE E SOCIEDADE, 5., 2010, Florianópolis/SC. Anais... Florianópolis: ANPPAS, 2010. Disponível em: <http://www.anppas.org.br/encontro5/cd/artigos/GT15-59-2920100809153102 .pdf $>$. Acesso em: 28 dez. 2015.

SILVA, J. A. Bens de Interesse Público e Meio Ambiente. In: Revista Crítica Jurídica. n.19. México: UNAM, 2001. P. 159-162. Disponível em: <http://www.juridicas.unam. $\mathrm{mx} / \mathrm{publica} / \mathrm{librev} / \mathrm{rev} / \mathrm{critica} / \mathrm{cont} / 19 / \mathrm{ana} / \mathrm{ana} 9 . \mathrm{pdf}>$. Acesso em: $09 \mathrm{dez} .2015$. 
SOUZA FILHO, C. F. M. de. Bens culturais e proteçáo jurídica. Porto Alegre: Unidade Editorial, 1997.

UICN. União Internacional para a Conservação da Natureza. Guidelines for Applying Protected Area Management Categories. Suíça: Page Bros, 2008. Disponível em: $<$ https://portals.iucn.org/library/sites/library/files/documents/PAPS-016.pdf>. Acesso em 27 dez 2016.

UNESCO. Convenção para a Proteção do Patrimônio Mundial, Cultural e Natural. UNESCO, 1972. Disponível em: <http://whc.unesco.org/archive/convention-pt.pdf>. Acesso em: 05 nov. 2015.

. Directrices Prácticas para la aplicación de la Convención del Patrimonio Mundial. UNESCO, 1977. Versão publicada em 02 fev. 2005. Disponível em: <http:// whc.unesco.org/archive/opguide05-es.pdf>. Acesso em: 02 jan 2016.

. Patrimônio Cultural Subaquático. 2001. Disponível em: <http://www.unesco. $\mathrm{org} /$ new/es/culture/themes/underwater-cultural-heritage/2001-convention/official-text/>. Acesso em: 06 dez. 2015.

. Convenção para Salvaguarda do Patrimônio Cultural Imaterial. UNESCO, 2003. Disponível em: <http://portal.iphan.gov.br/uploads/ckfinder/arquivos/ Convencao\%20Salvaguarda\%20Patrim\%20Cult\%20Imaterial\%202003.pdf>. Acesso em: 06 dez. 2015.

. Patrimônio Cultural Imaterial. UNESCO. Disponível em: <http://www. unesco.org/new/pt/brasilia/culture/world-heritage/intangible-heritage/>. Acesso em: 06 dez. 2015.

Properties inscribed on the World Heritage List (19): Brazil. UNESCO.

Disponível em: <http://whc.unesco.org/en/statesparties/BR/>. Acesso em: $06 \mathrm{dez} .2015$.

. Patrimônio natural no Brasil. 2016. Disponível em: <http://www.unesco.org/ new/pt/brasilia/natural-sciences/environment/natural-heritage/\#c1076385>. Acesso em: 06 dez. 2015.

ZANIRATO, S. H. Patrimônio da Humanidade: Controvérsias Conceituais e Legais na Definição de Bem Comum. In: ENCONTRO DA ASSOCIAÇÃO NACIONAL DE PÓS-GRADUAÇÃO E PESQUISA EM AMBIENTE E SOCIEDADE, 5., 2010, Florianópolis. Anais... Florianópolis: ANNPAS, 2010. Disponível em: <http://www. anppas.org.br/encontro5/cd/artigos/GT15-359-289-20100902115329.pdf>. Acesso em: $02 / 11 / 2015$. 